CLINICAL STUDY

\title{
The clinical spectrum of RET proto-oncogene mutations in codon 790
}

Hélène Bihan, Arnaud Murat ${ }^{1}$, Marinos Fysekidis, Abdallah Al-Salameh, Claire Schwartz ${ }^{2}$, Eric Baudin ${ }^{3}$, Philippe Thieblot $^{4}$, Françoise Borson-Chazot ${ }^{5}$, Pierre-Jean Guillausseau ${ }^{6}$, Catherine Cardot-Bauters ${ }^{7}$, Isabelle Raingeard ${ }^{8}$, Elisabeth Requeda ${ }^{9}$, Jean Louis Sadoul ${ }^{10}$, Yves Reznik ${ }^{11}$ and Régis Cohen for the French Group of Endocrine Tumours (GTE)

Department of Endocrinology, Diabetes Mellitus and Metabolic Diseases, Avicenne Hospital, 125 route de Stalingrad, 93009 Bobigny Cedex, France, ${ }^{1}$ CHU Nantes, Nantes, France, ${ }^{2}$ Institut Godinot, Reims, France, ${ }^{3}$ Institut Gustave Roussy, Villejuif, France, ${ }^{4} \mathrm{CHU}$ Clermont-Ferrand, Clermont-Ferrand, France, ${ }^{5} \mathrm{CHU}$ Lyon, Lyon, France, ${ }^{6} \mathrm{Hôpital} \mathrm{Lariboisière,} \mathrm{Paris,} \mathrm{France,}{ }^{7} \mathrm{CHRU}$ Lille, Lille, France, ${ }^{8} \mathrm{CHU}$ Montpellier, Montpellier, France, ${ }^{9} \mathrm{CH}$ Sud Francilien, Corbeil-Essonne, France, ${ }^{10} \mathrm{CHU}$ Nice, Nice, France and ${ }^{11} \mathrm{CHU}$ Caen, Caen, France

(Correspondence should be addressed to H Bihan; Email: helene.bihan@avc.aphp.fr)

\begin{abstract}
Objective: Due to a strong genotype-phenotype correlation, the timing of prophylactic thyroidectomy in rearranged during transfection $(R E T)$ gene mutation carriers is usually dictated by genetic analysis. Subjects and methods: We report a nationwide retrospective study of the clinical data of 77 French patients from 19 families with a mutation in codon 790 of the RET proto-oncogene.

Results: The average age at diagnosis was 35.6 years \pm 20.5 . Thirty-nine patients were women. Fiftyfive patients underwent operations for the treatment of medullary thyroid carcinoma (MTC) at the mean age of 38 years (4-82 years). The mean follow-up duration was 89 months. TNM staging was as follows: TONxMx in 19, TxNxMx in 1, T1NxMx in 22, T1N1Mx in 8, T2N1Mx in 1 and T3N1Mx in four patients. In the $\mathrm{T} 1 / \mathrm{x}-\mathrm{Nx}$ group, $96 \%$ were considered cured after surgery. In the N1 group $(n=13)$, six patients had multifocal disease and five patients were cured. Age and gender were not significant predictors of remission. Twenty-two patients did not undergo an operation (age 1.5-78 years); among them, 11 patients had a mean basal calcitonin (CT) level of $9.8 \mathrm{pg} / \mathrm{ml}(2-24)$ after 53 months of follow-up. One patient had been operated on for phaeochromocytoma (PHEO), and their CT level remained normal for 262 months.

Conclusions: This study confirms that RET 790 mutation is associated with a non-aggressive form of multiple endocrine neoplasia type 2 , as $28 \%$ of the patients were followed up without thyroidectomy, $25 \%$ had been thyroidectomised with no tumour being detected and even patients with MTC had slowevolving disease. Moreover, only one patient had PHEO, and no-one had primary hyperparathyroidism.
\end{abstract}

European Journal of Endocrinology 169 271-276

\section{Introduction}

Autosomal-dominant gain-of-function mutations in the rearranged during transfection (RET) proto-oncogene lead to medullary thyroid carcinoma (MTC). RET mutations have been divided into three risk groups: high risk (mutations in codons 883 and 918), moderate risk (mutations in codons 611, 618, 620 and 634), low risk (mutations in codons 609, 768, 790, 791, 804 and 891), for which prophylactic thyroidectomy is recommended before the age of 2 months, 5 years and 10 years respectively (1). After 18 years of recommending prophylactic thyroid surgery in gene carriers, the American Thyroid Association (ATA) has refined this position. The ATA has published recommendations on the timing of prophylactic thyroidectomy and the extent of surgery, which were based on genotype-phenotype correlations that stratify mutations into four risk levels
(A, B, C and D) (2). These recommendations have led to the development of the concept of safely delaying prophylactic thyroidectomy while offering careful expectant monitoring in children with risk level $\mathrm{A}$ and B mutations. This approach seems to be logical in children with normal calcitonin (CT) levels, normal neck ultrasonography and a less aggressive MTC family history, in whom the chance of identifying MTC is low (3).

RET 790 mutation has been described for the first time in 1997 in a patient with sporadic phaeochromocytoma (PHEO) without other MEN-2 features (4). The mutation represents the second or third most prevalent RET mutation. In the EUROMEN study, which included a group of 207 carriers aged below 20 years, the prevalence of RET 790 mutation was $6.8 \%$ (5), but in another recent report, the mutation represented $12 \%$ of all the mutations (6). This mutation belongs to the 
low-risk level A according to the ATA stratification and to level 1 according to the 7th International Workshop on MEN-2. Although some single cases with more aggressive presentation have been reported (e.g. MTC with lymph node metastasis was diagnosed in a 10-year-old boy) (5), RET 790 mutation appears to confer a low risk for MTC in most cases, raising the question as to whether thyroidectomy should be optional. Among 15 carriers from one family, two subjects aged above 70 years who did not undergo thyroidectomy had only moderately elevated CT levels (7).

The current investigation was undertaken to provide the natural history data, which are urgently needed to enable factual decision-making about the timing of prophylactic surgery in patients who have tested positive for RET germline mutations (8). We carried out a national retrospective study on French carriers with the primary objective of analysing the natural history of RET 790 mutation carriers, including both those who had undergone thyroidectomy and those who had not. The secondary objective was to describe the practice of prophylactic thyroidectomy in the French institutions and to find predictive factor(s) that could help discriminate cases with no C-cell pathology, intrathyroidal disease or extrathyroidal disease.

\section{Subjects and methods}

\section{Study population}

This multi-centre, longitudinal, retrospective, observational survey of RET 790 mutation carriers was conducted by the French Group of Endocrine Tumours (GTE).

The inclusion criteria were as follows: i) an identified germline RET 790 mutation and ii) completion of a form by a clinician. The survey included carrier patients who had undergone thyroidectomy from October 1987 to January 2011 and carriers who did not undergo an operation. Patient inclusion was terminated in January 2011. Another round of data collection was undertaken at the end of 2011. Patients $(n=85)$ were identified from existing databases by each GTE team at 13 French centres. After the second round of data collection (April 2012), eight patients were excluded due to insufficient information.

For every patient, the following characteristics were recorded: age, gender, date of birth, date of surgery, preoperative basal and/or pentagastrin-stimulated CT (CT/Pg) levels (assessment was performed locally), extension of surgery, morbidity, pTNM staging, postoperative basal CT and CT/Pg levels, and mortality information. CT and pentagastrin (Pg) stimulation tests and mutation analysis were carried out in accordance with national guidelines concerning testing methods, but also, and most importantly, in accordance with guidelines concerning the required informed and written consent of every patient or his or her legal guardian.

CT levels were determined using an IRMA (IRMACIS-Biointernational, Gif-Sur-Yvette, France), except in two patients who had undergone surgery before 1988 $(9,10)$. Basal or $\mathrm{CT} / \mathrm{Pg}$ levels above $10 \mathrm{pg} / \mathrm{ml}$ were considered abnormal in the postoperative period in all the patients. These patients were defined as non-cured.

The time and type of neck surgery performed were according to the centre's policy in accordance with the patients and/or their families who were informed of the low aggressiveness of the disease. Data on lymph node dissection (whether performed and its extent) were collected; these data included NO, N1 and Nx (nonconclusive data). For analysis, the Nx classification was used to describe the NO and/or Nx data. The same approach was applied for metastasis. Tumour staging was performed according to the 2010 UICC TNM classification (11). C-cell hyperplasia (CCH) was defined as the presence of at least $50 \mathrm{C}$ cells in a single lowpower field $(\times 100$ magnification).

For analysis, the patients were divided into two groups: the first group included operated patients and the second group included non-operated patients. The patients in the latter group refused surgery or surgery was not proposed by the clinician. An annual follow-up was performed and included a clinical examination and a biochemical evaluation.

\section{Statistical analyses}

All statistical analyses were performed using SPSS, Inc. The Mann-Whitney $U$ test and the $t$-test were used according to the normality of the continuous variables analysed. A $P$ value $<0.05$ was considered statistically significant. Receiver operating characteristic (ROC) curves were used to compare the diagnostic value of serum CT and age at surgery for achieving cure. The optimal cut-off scores as well as sensitivity and specificity were determined. Patients classified as NO or $\mathrm{Nx}$ were analysed together and referred to as $\mathrm{Nx}$ in describing their collective statistical analysis results.

\section{Results}

\section{All the population}

Overall, 77 patients from 13 centres were included in this study, representing 19 families (Table 1), with seven index patients and 70 screening patients. Their mean age was 35.6 years \pm 20.5 . Thirty-nine of the patients were women. Fifty-five patients had undergone an operation and 22 had not. Nine patients were lost to follow-up after diagnosis or surgery. There were no deaths due to MTC or other causes during follow-up. 
Table 1 Characteristics of the patients. Age: age at diagnosis for non-operated patients and age at surgery for the others. CT/Pg and CT levels after pentagastrin stimulation.

\begin{tabular}{|c|c|c|c|c|c|c|c|c|}
\hline & \multirow[b]{2}{*}{$n$} & \multirow[b]{2}{*}{ Age } & \multicolumn{2}{|c|}{$\begin{array}{l}\text { Preoperative or baseline data for } \\
\text { non-operated patients }\end{array}$} & \multicolumn{2}{|c|}{$\begin{array}{l}\text { Postoperative or data during } \\
\text { follow-up in non-operated patients }\end{array}$} & \multirow[b]{2}{*}{$\begin{array}{l}\text { Follow-up } \\
\text { (months) }\end{array}$} & \multirow[b]{2}{*}{ Not cured } \\
\hline & & & CT (pg/ml) & $\mathrm{CT} / \mathrm{Pg}$ & CT & $\mathrm{CT} / \mathrm{Pg}$ & & \\
\hline Non-operated & 22 & $30(1.5-78)$ & $7.88(0-14)$ & $22.5(0-70)$ & $10.8(2-29)$ & $53.0(20.2-104)$ & $57(3-262)$ & $\begin{array}{l}\text { Six lost to } \\
\text { follow-up }\end{array}$ \\
\hline Operated & 55 & $38(4-82)$ & 387 (1.9-7892) & $1616.6(10.6-10$ 870) & $36.3(1.5-1360)$ & $4(0-7)$ & $89(1-238)$ & 9 \\
\hline No tumour & 19 & $46(24-76)$ & $5.2(1.9-11)$ & $28.8(10.6-47)$ & $2.44(1.5-5)$ & $1.5(0-3)$ & $79(1.6-164)$ & 0 \\
\hline TNM ND & 1 & 56 & 156 & & 5 & & 8 & 0 \\
\hline T1N0/Nx & 22 & $45(18-74)$ & $92.4(5-356)$ & $324.4(66-935)$ & $5(2-12)$ & $5(3-7)$ & $83(1-187)$ & 1 \\
\hline T1N1 & 8 & $51(32-70)$ & $212(204-220)$ & $2000(n=1)$ & $190(2-1360)$ & NA & $133(16-238)$ & 4 \\
\hline $\mathrm{T} 2 \mathrm{~N} 1$ & 1 & 33 & ND & ND & 2 & NA & 224 & 1 \\
\hline T3N1 & 4 & $64(48-82)$ & 2848 (392-7892) & $10870(n=1)$ & $42.9(3.6-95)$ & NA & $61(2-160)$ & 3 \\
\hline
\end{tabular}

ND, not determined.

\section{Surgery group}

Fifty-five patients had undergone an operation for the treatment of MTC. Their ages ranged between 4 and 82 years, with a mean age of 38.4 years and a mean follow-up duration of 88.9 months (range 1.0-237.6 months; Fig. 1).

TNM staging was as follows: TONxMx in 19, TxNxMx in $1, \mathrm{~T} 1 \mathrm{NxMx}$ in 22 , T1N1Mx in $8, \mathrm{~T} 2 \mathrm{~N} 1 \mathrm{Mx}$ in 1 and T3N1Mx in four patients. Lymph node dissection was performed in 42 patients (15 central, one central and unilateral, 23 central and bilateral, and three lymph node dissections without precision), and 13 patients had not undergone lymph node dissection. In addition, one patient had undergone an operation before the age of 5 years, three patients between 5 and 10 years and eight patients between 10 and 20 years.

Surgical complications occurred in one patient who suffered transient hypoparathyroidism. Among the 19 TONx patients, $\mathrm{CCH}$ was present in 16 , and all the 16 patients had normal basal CT (16/16) and/or CT/Pg (12/12) values. For the other three patients, no information was available. Bilateral $\mathrm{CCH}$ was evident in 13 of the 16 patients, and unilateral $\mathrm{CCH}$ was present in three patients.

$\mathrm{T}$ and $\mathrm{N}$ status was associated with cure. Nx patients were not younger than those classified as N1 (mean age 48.3 years (range $18-70$ years) vs 52.2 years $(32-82$ years), NS). In the Nx group, $96 \%$ of the patients were considered cured after surgery $(22 / 23)$, with a mean follow-up duration of 80.5 months based on the CT levels, whereas in the N1 group $(n=13)$, six patients had multifocal disease, and five of the 13 patients were cured. Four patients were lost to follow-up immediately after surgery. Age $<30$ years was a significant factor to predict cure according to the ROC analysis (sensibility $100 \%$, specificity $45.7 \%, P=0.02$ ). According to the ROC analysis, the best cut-off of preoperative basal CT levels for predicting cure was $33 \mathrm{pg} / \mathrm{ml}$ (sensibility $100 \%$, specificity $76.2 \%, P \leq 0.0001)$.
The youngest age at diagnosis of MTC was 24 years. Concerning lymph nodes, 32 years was the youngest age for lymph node involvement and $43 \mathrm{pg} / \mathrm{ml}$ was the lowest CT value associated with lymph node involvement. The highest CT value allowing for cure was $623 \mathrm{pg} / \mathrm{ml}$.

The data of the nine non-cured patients revealed that they had high preoperative CT levels, except two patients whose CT levels were lower than $100 \mathrm{pg} / \mathrm{ml}$. However, the tumour size was relatively small, with a mean size of $12.4 \mathrm{~mm}$ (5-30) (Table 2).

\section{Index cases}

Seven patients were index cases (three males and four females), with a mean age of 57.4 years (40-73). All had been operated on, with a MTC classified as T1N0 for three, T1N1 for two and T3N1 for two patients. Preoperative and postoperative CT levels

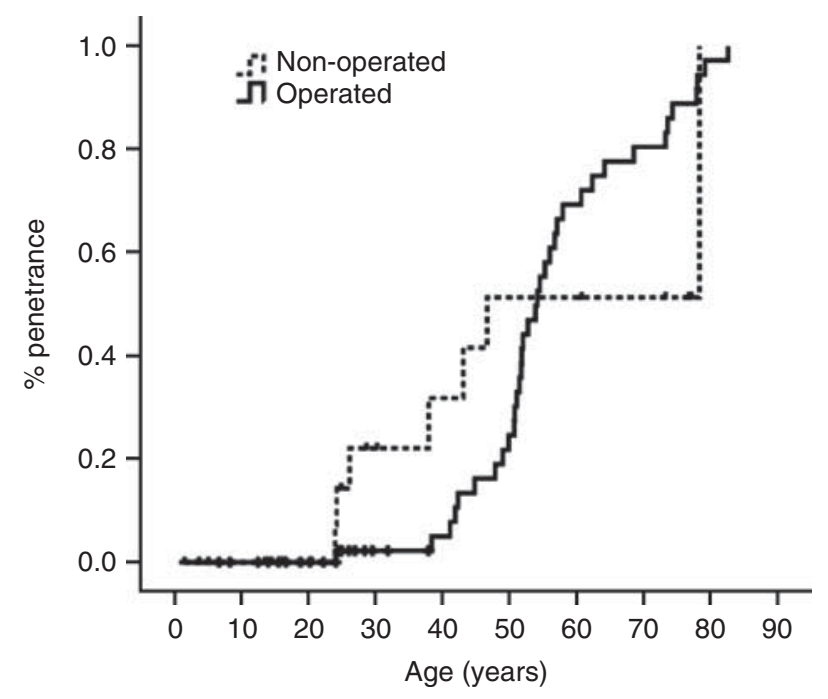

Figure 1 Penetrance of MTC (operated patients) or elevated calcitonin levels $>10 \mathrm{pg} / \mathrm{ml}$ (non-operated patients) in RET 790 gene carriers. 
Table 2 Data of the non-cured patients (classified by age at surgery).

\begin{tabular}{|c|c|c|c|c|c|c|c|c|c|c|}
\hline & Gender & Age & $\begin{array}{l}\text { Preoperative } \\
\text { CT }(\mathrm{pg} / \mathrm{ml})\end{array}$ & $\begin{array}{c}\text { Preoperative } \\
\text { CT/Pg }\end{array}$ & TNM & $\begin{array}{c}\text { Tumour } \\
\text { size }(\mathrm{mm})\end{array}$ & $\begin{array}{l}\text { Postopera- } \\
\text { tive CT }\end{array}$ & $\begin{array}{c}\text { Postoperative } \\
\text { CT/Pg }\end{array}$ & Comments & $\begin{array}{c}\text { Follow-up } \\
\text { (months) }\end{array}$ \\
\hline Patient 1 & $M$ & 32 & 43 & 332 & T1N1M0 & 5 & 9.5 & 131 & & 202 \\
\hline Patient 2 & $\mathrm{~F}$ & 33 & ND & ND & T2N1M0 & & 2 & 454 & & 224 \\
\hline Patient 3 & $\mathrm{~F}$ & 35 & 204 & 2000 & T1N1M0 & 10 & 127 & & Reoperation & 122 \\
\hline Patient 4 & $\mathrm{~F}$ & 48 & 759 & 10870 & T3N1Mx & 30 & 79 & & Reoperation & 160 \\
\hline Patient 5 & $M$ & 49 & 117 & ND & T1N0M0 & 7 & 12 & 286 & & 68 \\
\hline Patient 7 & $M$ & 56 & 1779 & 5018 & T1N1M0 & 10 & 1360 & & 4 Operations & 238 \\
\hline Patient 8 & $\mathrm{~F}$ & 65 & 392 & ND & T3N1Mx & 13 & 34 & & & 38 \\
\hline Patient 9 & $M$ & 82 & 7892 & ND & T3N1bM0 & & 95 & & & 2 \\
\hline
\end{tabular}

ND, not determined.

were respectively $1554.5 \mathrm{pg} / \mathrm{ml} \mathrm{(759-2350)}$ and $208.8 \mathrm{pg} / \mathrm{ml}(2-1360)$. The mean follow-up duration was 124 months (35-237); two were not cured.

\section{Non-operated patients}

Twenty-two patients had not undergone an operation (age range 1.5-78 years). The mean follow-up duration was 57 months for 16 patients. At diagnosis, basal CT levels were normal in 18 of the 20 patients evaluated. Nine patients had undergone a Pg stimulation test, the results of which were normal for eight patients. One patient had elevated stimulated Pg levels $(70 \mathrm{pg} / \mathrm{ml}$, $n<30 \mathrm{pg} / \mathrm{ml}$ - her basal CT levels were normal, at $10 \mathrm{pg} / \mathrm{ml}$ ). During the follow-up, ten patients had normal basal CT levels, three patients had abnormal basal CT levels $(19-29 \mathrm{pg} / \mathrm{ml})$ and four patients had abnormal stimulated CT levels (41-104 pg/ml; Fig. 1). The follow-up duration ranged from 6 to 62 months. Six patients had no follow-up.

\section{Miscellaneous}

Only one patient had PHEO, which had been removed surgically in 1979. It is noteworthy that this patient was the first patient identified in the literature as a RET 790 mutation carrier. Genetic testing was motivated by the occurrence of PHEO at a young age. Because of the lack of abnormalities during thyroid US and the normal CT levels, no thyroid surgery was performed and nor was familial screening undertaken. The follow-up duration of this case was 262 months (more than 20 years). Except for this patient, no other patient in this series had PHEO or hyperparathyroidism (HPTH). Four patients had other carcinomas: vesicular thyroid carcinoma (two patients), renal adenocarcinoma (one patient) and oesophageal carcinoma (one patient). Two patients had autoimmune thyroiditis.

\section{Discussion}

To provide appropriate guidelines for specific mutations, it is important to have a large cohort with a long follow-up period. Our study is important in this regard, as we analysed the largest series ever studied with the RET 790 proto-oncogene mutation, which might be the third most prevalent RET mutation (at least in some countries, such as Germany). The other novelty of our study was the follow-up of patients who had undergone surgery and those who did not (mean follow-up duration of 53 and 111 months respectively).

The present study has many implications. First, our results confirm the low penetrance of this mutation, as reported by us and others $(7,11,12)$. Frank-Raue et al. (12) described 47 patients with mutations in RET codon 790; the median age at diagnosis was 57 years for the 16 index patients. The earliest age at onset was 12 years for a screening patient, but a 41-year-old patient remained without a tumour (12). Second, our results support other reports that indicate the low aggressiveness of this mutation. For example, the mean age at diagnosis was 35.6 years in our study, and it was 39 years in the study of Machens et al. (2001) (8). The mean age at surgery was 38.4 years in our study, compared with 34 years in the study of Brauckhoff $e t$ al. (2002) (13). In addition, we observed a mean N1 patient age of 52.2 years, compared with 59.4 years in the study of Gimm et al. (14). Third, the low penetrance of the MEN-2A phenotype was confirmed, as only one PHEO case was detected, in a patient who was 27 years old at the time but who is now 61 years old without MTC. We also observed no cases of primary HPTH. Of note, primary HPTH has never been reported in RET 790 mutation carriers (15), and PHEO is only rarely associated with this genotype (16). We confirmed that screening for HPTH is not necessary, and because PHEO rarely occurs, screening might be needed only in case of hypertension or clinical signs. Another option would be to screen for PHEO at longer intervals (every 5 years).

Finally, variability in the phenotypes of RET 790 mutation carriers was observed: lymph node metastases at 10 years in one report (5) vs many patients without evidence of disease, as well as six patients aged above 60 years who were operated on in this study (four patients classified as T1 and two patients classified as T3). Ten patients were aged above 55 years (all had undergone surgery except one), and four patients were aged above 
70 years (all surgical recipients). Cure was observed in seven patients aged above 55 years and in three of four patients aged above 70 years. Whether this variability is due to a genetic modifier or the presence of other somatic mutations is unknown, and our study was not designed to answer this question. We did not analyse the relationship between the type of RET 790 mutation $(\mathrm{TTG} \rightarrow \mathrm{TTT}$ or $\mathrm{TTG} \rightarrow \mathrm{TTC}$ ) and phenotype. However, both missense mutations lead to the same amino acid change, so the functional differences, if any, between the mutations should be limited.

It is now well accepted that prophylactic thyroidectomy at 5 years or even 10 years leads to overtreatment in patients with RET 790 mutation. This overtreatment is one of the drawbacks of the current DNA-based approach. Another drawback is that geneticbased guidelines give no clear information about lymph node dissection. Therefore, biochemical data should be integrated with genetic data to achieve cure while avoiding the risk of overtreatment and the long-term complications of thyroidectomy. One interesting idea would be to provide necessary therapy one step earlier than the spread of disease. The ROC analysis indicated that for patients who had undergone an operation, a preoperative basal $\mathrm{CT}$ level of $33 \mathrm{pg} / \mathrm{ml}$ (sensibility $100 \%$, specificity $76.2 \%, P \leq 0.0001$ ) was predictive of cure. These results indicate that if RET 790 mutation carriers have a normal CT level, they could be followed up with a surveillance protocol instead of being treated with surgery (careful watching while waiting), while patients with mildly elevated CT levels but below the proposed cut-off could be followed up or treated with total thyroidectomy without lymph node dissection. Patients found to have CT levels above the cut-off should undergo a total thyroidectomy with lymph node dissection. This level is close to the published levels that are associated with cure in all the MTC forms (50 pg/ml (17) and in familial forms: $40 \mathrm{pg} / \mathrm{ml}$ (2), $31 \mathrm{pg} / \mathrm{ml}$ (18) or $10 \mathrm{pg} / \mathrm{ml}$ (19)). Moreover, Machens et al. (2009) (16) found that CT levels were at $41.2 \mathrm{pg} / \mathrm{ml}$ (29.2-53.1) and $53.9 \mathrm{pg} / \mathrm{ml}$ (45.6-62.3) in patients with MTC pNO and MTC pN1 respectively. The relatively long time intervals from NO to N1 of 33 and 50 years in this report and 31 and 56 years in another report published in 2007 by Machens \& Dralle (20) are facts that confirm the low aggressiveness of RET 790 mutation and support the above-mentioned approach.

Our study has some limitations. First, its retrospective nature provides heterogeneity in patients' management and does not reflect the 2012 situation. Most centres follow a clinical approach, not directed by research issues. French law prohibits direct contact with other family members, even for screening purposes, because any relevant information can be provided only by the index patient. Second, the determination of lymph node status was more complex and inconsistently carried out compared with that of the T status, as performing lymph node dissection depends on local practices and surgeon's experience. Third, many patients were censored during follow-up (whether they were lost, left the study or had no recurrence at the end of the study), which reduced the sample size of at-risk patients. However, censoring was mainly observed in $\mathrm{CCH}$, in normal patients and in the $\mathrm{Nx}$ groups. Thus, the potential bias introduced by censored patients is limited, leading to a good estimation of disease-free survival. Another limitation is the absence of any information about somatic RET mutations that might have modulated the clinical course in some patients (a RET 790 mutation carrier would eventually have an aggressive form if there is another somatic mutation).

We conclude that RET 790 mutation is only associated with a very low-risk MTC with other exceptional MEN-2-related features. MTC was detected in fewer than $50 \%$ of the carriers and was found to have a non-invading, slowly progressive, benign course. The other half of our patients were either operated on without MTC detection or not operated on but doing well. Simple surveillance is safe in patients with normal or slightly increased CT levels, and thyroidectomy is sufficient in patients with mildly elevated CT levels $(<33 \mathrm{pg} / \mathrm{ml})$, with no need for the performance of lymph node dissection in such patients.

\section{Declaration of interest}

The authors declare that there is no conflict of interest that could be perceived as prejudicing the impartiality of the research reported.

\section{Funding}

This research did not receive any specific grant from any funding agency in the public, commercial or not-for-profit sector.

\section{Author contribution statement}

$\mathrm{R}$ Cohen and A Murat collected the data, with the contribution of all the authors. H Bihan, R Cohen and M Fysekidis analysed the results. M Fysekidis performed all the statistical analyses. H Bihan, R Cohen and A Al-Salameh wrote the paper. $\mathrm{H}$ Bihan has primary responsibility for its final content. All authors read and approved the final manuscript.

\section{Acknowledgements}

The authors are very grateful to all of the clinicians who provided data and to the patients who helped in data collection and especially to Dr Anne Paule GIMENEZ-ROQUEPLO, Hôpital Européen Georges Pompidou, for carrying out genetic studies.

\section{References}

1 Brandi ML, Gagel RF, Angeli A, Bilezikian JP, Beck-Peccoz P, Bordi C, Conte-Devolx B, Falchetti A, Gheri RG, Libroia A et al. Guidelines for diagnosis and therapy of MEN type 1 and type 2 . Journal of Clinical Endocrinology and Metabolism 200186 5658-5671. (doi:10.1210/jc.86.12.5658)

2 American Thyroid Association Guidelines Task Force, Kloos RT, Eng C, Evans DB, Francis GL, Gagel RF, Gharib H, Moley JF, 
Pacini F, Ringel MD et al. Medullary thyroid cancer: management guidelines of the American Thyroid Association. Thyroid 200919 565-612. (doi:10.1089/thy.2008.0403)

3 Grubbs EG, Waguespack SG, Rich TA, Xing Y, Ying AK, Evans DB, Lee JE \& Perrier ND. Do the recent American Thyroid Association (ATA) Guidelines accurately guide the timing of prophylactic thyroidectomy in MEN2A? Surgery $2010 \mathbf{1 4 8} 1302-1310$. (doi:10.1016/j.surg.2010.09.020)

4 Rodien P, Jeunemaitre X, Dumont C, Beldjord C \& Plouin PF. Genetic alterations of the RET proto-oncogene in familial and sporadic pheochromocytomas. Hormone Research $1997 \mathbf{4 7}$ 263-268. (doi:10.1159/000185474)

5 Machens A, Niccoli-Sire P, Hoegel J, Frank-Raue K, van Vroonhoven TJ, Roeher HD, Wahl RA, Lamesch P, Raue F, ConteDevolx B et al. Early malignant progression of hereditary medullary thyroid cancer. New England Journal of Medicine 2003 349 1517-1525. (doi:10.1056/NEJMoa012915)

6 Machens A \& Dralle H. Familial prevalence and age of RET germline mutations: implications for screening. Clinical Endocrinology $2008 \quad 69$ 81-87. (doi:10.1111/j.1365-2265. 2007.03153.x)

7 Bihan H, Baudin E, Meas T, Leboulleux S, Al Ghuzlan A, Hannoteaux V, Travagli JP, Valleur P, Guillausseau PJ \& Cohen R. Role of prophylactic thyroidectomy in RET 790 familial medullary thyroid carcinoma. Head E Neck 201234 493-498. (doi:10.1002/hed.21763)

8 Machens A, Gimm O, Hinze R, Höppner W, Boehm BO \& Dralle H. Genotype-phenotype correlations in hereditary medullary thyroid carcinoma: oncological features and biochemical properties. Journal of Clinical Endocrinology and Metabolism $2001 \mathbf{8 6}$ 1104-1109. (doi:10.1210/jc.86.3.1104)

9 Motté P, Vauzelle P, Gardet P, Ghillani P, Caillou B, Parmentier C, Bohuon C \& Bellet D. Construction and clinical validation of a sensitive and specific assay for serum mature calcitonin using monoclonal anti-peptide antibodies. Clinica Chimica Acta 1988 174 35-54. (doi:10.1016/0009-8981(88)90365-8)

10 Guilloteau D, Perdrisot R, Calmettes C, Baulieu JL, Lecomte P, Kaphan G, Milhaud G, Besnard JC, Jallet P \& Bigorgne JC. Diagnosis of medullary carcinoma of the thyroid (MCT) by calcitonin assay using monoclonal antibodies: criteria for the pentagastrin stimulation test in hereditary MCT. Journal of Clinical Endocrinology and Metabolism $1990 \quad 71$ 1064-1067. (doi:10.1210/jcem-71-4-1064)

11 Berndt I, Reuter M, Saller B, Frank-Raue K, Groth P, Grussendorf M, Raue F, Ritter M \& Höppner W. A new hot spot for mutations in the ret protooncogene causing familial medullary thyroid carcinoma and multiple endocrine neoplasia type $2 \mathrm{~A}$. Journal of Clinical Endocrinology and Metabolism $1998 \mathbf{8 3}$ 770-774. (doi:10.1210/jc.83.3.770)

12 Frank-Raue K, Machens A, Scheuba C, Niederle B, Dralle H \& Raue F. Difference in development of medullary thyroid carcinoma among carriers of RET mutations in codons 790 and 791. Clinical Endocrinology 200869 259-263. (doi:10.1111/j.1365-2265. 2008.03215.x)

13 Brauckhoff M, Gimm O, Hinze R, Ukkat J, Brauckhoff K \& Dralle H. Papillary thyroid carcinoma in patients with RET proto-oncogene germline mutation. Thyroid 200212 557-561. (doi:10.1089/ 105072502320288393)

14 Gimm O, Niederle BE, Weber T, Bockhorn M, Ukkat J, Brauckhoff M \& Thanh PN. RET proto-oncogene mutations affecting codon 790/791: a mild form of multiple endocrine neoplasia type 2A syndrome? Surgery 2002132 952-959. (doi:10.1067/msy.2002. 128559)

15 Margraf RL, Crockett DK, Krautscheid PMF, Krautscheid PMF, Seamons R, Calderon FRO, Wittwer CT \& Mao R. Multiple endocrine neoplasia type 2 RET protooncogene database: repository of MEN2-associated RET sequence variation and reference for genotype/phenotype correlations. Human Mutation 200930 548-556. (doi:10.1002/humu.20928)

16 Machens A, Lorenz K \& Dralle H. Individualization of lymph node dissection in RET (rearranged during transfection) carriers at risk for medullary thyroid cancer: value of pretherapeutic calcitonin levels. Annals of Surgery 2009250 305-310. (doi:10.1097/SLA. Ob013e3181ae333f)

17 Cohen R, Campos JM, Salaün C, Heshmati M, Kraimps JL, Proye C, Sarfati E, Henry JF, Niccoli-Sire P \& Modigliani E. Preoperative calcitonin levels are predictive of tumor size and postoperative calcitonin normalization in medullary thyroid carcinoma. Groupe d'Etudes des Tumeurs a Calcitonine (GETC). Journal of Clinical Endocrinology and Metabolism 200085 919-922. (doi:10.1210/ jc.85.2.919)

18 Rohmer V, Vidal-Trecan G, Bourdelot A, Niccoli P, Murat A, Wemeau JL, Borson-Chazot F, Schvartz C, Tabarin A, Chabre O et al. Prognostic factors of disease-free survival after thyroidectomy in 170 young patients with a RET germline mutation: a multicenter study of the Groupe Francais d'Etude des Tumeurs Endocrines. Journal of Clinical Endocrinology and Metabolism 2011 96 E509-E518. (doi:10.1210/jc.2010-1234)

19 Machens A \& Dralle H. Prophylactic thyroidectomy in RET carriers at risk for hereditary medullary thyroid cancer. Thyroid 200919 551-554. (doi:10.1089/thy.2009.0144)

20 Machens A \& Dralle H. Genotype-phenotype based surgical concept of hereditary medullary thyroid carcinoma. World Journal of Surgery 200731 957-968. (doi:10.1007/s00268006-0769-y)

Received 16 January 2013

Revised version received 4 June 2013

Accepted 10 June 2013 